\title{
Observations of thermospheric neutral winds within the polar cusp and the auroral oval using a Doppler imaging system (DIS)
}

\author{
D. Rees ${ }^{1}$, R. W. Smith ${ }^{2}$, F. Signernes ${ }^{3}$, K. Henriksen ${ }^{\dagger 4}$, U. Brandstrom ${ }^{5}$, M. Harris ${ }^{6}$ and G. Maskall ${ }^{6}$ \\ ${ }^{1}$ Center for Atmospheric and Space Science, Utah State University, Logan, UT 84322-4405, USA \\ ${ }^{2}$ Geophysical Institute, University of Alaska, USA \\ ${ }^{3}$ University Courses in Svalbard, Longyearbyen, Svalbard \\ ${ }^{4}$ Institute for Math and Physical Sciences, University of Tromso, ${ }^{\dagger}$ (deceased) \\ ${ }^{5}$ Institute for Space Physics, Kiruna, Sweden \\ ${ }^{6}$ Hovemere Ltd, Keston, Bromley, Kent UK
}

Received: 29 October 1997 / Revised: 16 July 1998 / Accepted: 17 July 1998

\begin{abstract}
Two Doppler imaging systems (DIS) or widefield imaging Fabry-Perot interferometers (FPI), have recently been commissioned, one at the Auroral Station, Adventdalen, Longyearbyen, Svalbard, and the second at the IRF, Kiruna, Sweden. These instruments can provide wide-field $(600 * 800 \mathrm{~km})$ images of neutral wind flows in the upper thermosphere, by measuring the Doppler shift of the atomic oxygen forbidden near $630 \mathrm{~nm}$, which is emitted from an altitude of approximately $240 \mathrm{~km}$. From the instrument in Svalbard, at mid-winter, it is possible to observe the dayside polar cusp and the polar cap throughout the entire day, whereas from Kiruna, the night-time auroral oval is observable during the hours of darkness. Measurements of thermospheric dynamics from the DIS can be used in conjunction with observations of ionospheric plasma flows and thermal plasma densities by the EISCATSvalbard radar (ESR) and by EISCAT, along with other complementary observations by co-located instruments such as the auroral large-scale imaging system (ALIS). Such combined data sets will allow a wide range of scientific studies to be performed concerning the dynamical response of the thermosphere and ionosphere, and the important energetic and momentum exchange processes resulting from their complex interactions. These processes are particularly important in the immediate vicinity of the polar cusp and within the auroral oval. Early results from Svalbard in late 1995 will be discussed. The DIS in Kiruna observed two interesting geomagnetic disturbances in early 1997, the minor geomagnetic storm of 10,11 January, and the disturbed period from 7-10 February. During these events, the thermospheric wind response showed some interesting departures from the average behaviour, which we attribute to the result of strong and variable
\end{abstract}

Correspondence to: David Rees, Walnut Tree Cottage, Jackass Lane, Keston, Bromley, Kent, UK, BR2 6AN E-mail: walnut1@easynet.co.uk, drees@walnut2.u-net.com
Lorenz forcing (ion drag) and Joule and particle heating during these geomagnetic disturbances.

Key words. Ionosphere (Polar ionosphere) ·

Meteorology and atmospheric dynamics (thermospheric dynamics; instruments and techniques).

\section{Introduction}

The Doppler imaging system (DIS) is a field-widened Fabry-Perot interferometer (FPI). It is based on a concept described initially by Rees and Greenaway (1983) and Rees et al. (1989, 1997). Two DIS instruments have been in routine winter-time operation since late 1995, one at the Nordlysstajonen, Adventdalen, Longyearbyen, Svalbard $\left(16^{\circ} \mathrm{E}, 78^{\circ} \mathrm{N}\right)$, and the second at the IRF, Kiruna $\left(20^{\circ} \mathrm{E}, 67^{\circ} \mathrm{N}\right)$.

The DIS records the high-resolution spectra of a selected spectral upper atmospheric emission produced by aeronomic, auroral, or resonance processes. Both DIS instruments in current operation use the atomic oxygen OI $\left({ }^{1} \mathrm{D}-{ }^{3} \mathrm{P}\right)$ emission at $630 \mathrm{~nm}$, commonly assumed to be generated within a broad region in the upper thermosphere between approximately 200 and $320 \mathrm{~km}$ altitude. The peak emission altitude of OI $\left({ }^{1} \mathrm{D}-{ }^{3} \mathrm{P}\right)$ emission generated by airglow processes is close to $240 \mathrm{~km}$ altitude, and the FWHM of the emission layer is around $40 \mathrm{~km}$. Under conditions of intense precipitation of soft auroral electrons, the mean emission altitude may decrease, but will never be lower than approximately $200 \mathrm{~km}$, due to the collisional deactivation of the atoms from the metastable level.

As with a conventional Fabry-Perot interferometer (FPI), the DIS determines the neutral wind by measuring the Doppler shift of the recorded spectra. The similarities and contrasts between the use of a conven- 
tional FPI and a DIS for upper atmospheric wind measurements have been described by Rees et al. (1989, 1997). The former paper also reviews the general background to the use of the Fabry-Perot interferometer for measurements of upper atmospheric winds. The DIS uses a wide-angle (fish-eye) lens to accept light from a solid angle of up to $75^{\circ}$ half-angle, centred on the zenith. The telecentric optical system ahead of the Fabry-Perot etalon transforms the light from this large solid angle in the far-field to illuminate several fringes (normally six to eight) produced by the Fabry-Perot etalon. The field-ofview (f-o-v) represented by these fringes (within the etalon) is approximately $2^{\circ}$ full angle. These FabryPerot fringes are then imaged onto a cooled, intensified, low-noise CCD detector, which integrates and records the relatively weak OI $\left({ }^{1} \mathrm{D}-{ }^{3} \mathrm{P}\right)$ emission.

Figure 1 displays a single image of the sky taken by the DIS in Svalbard during a long observing sequence on December 4, 1995. This image is representative of the images which contain the data which have to be processed in order to obtain thermospheric wind information. The image is obtained in the light of the oxygen OI $\left({ }^{1} \mathrm{D}-{ }^{3} \mathrm{P}\right)$ emission at $630 \mathrm{~nm}$, and contains a lowcontrast feature, the broad auroral arc stretching more or less east-west across this image, which is typical of the OI $\left({ }^{1} \mathrm{D}^{3} \mathrm{P}\right)$ images obtained by the DIS. There is moderate vignetting, a characteristic of "fish-eye" lens systems. Another important characteristic is the 10:1 intensity ratio from the brightest to the weakest fringes within a given image. This means that the signal-to-noise ratio of individual fringes varies considerably within a single image. A considerable variation of signal-to-noise ratio also occurs depending on auroral activity. At times of intense soft electron precipitation, it is also very important to avoid detector saturation, while the instrument still has to work efficiently at times of very weak airglow emission levels which occur at solar minimum, "mid-latitude" and at night time.
The geometric projection between the instrument and the far-field screen created by the atomic oxygen airglow layer near $240 \mathrm{~km}$ altitude is illustrated in Fig. 2. North is at the top, and east to the left. The five "central" fringes are imaged onto the sensitive surface of the ICCD, while the sectors of fringes six to eight are progressively cut off by the edges of the detector in the north-south direction, although these fringes are imaged in the "east-west" direction.

As shown in Fig. 2, the DIS maps each successive Fabry-Perot fringe (order of interference) onto a circle (approximately) in the airglow/auroral emission layer, centred above the observing station. If we consider the airglow layer to be a screen, of mean altitude $240 \mathrm{~km}$, the first or central fringe is projected relatively close to the zenith. As we move from the centre of the FabryPerot image, each successive fringe, produced as the interference order changes, maps to an approximate circle of progressively larger diameter, and thus a greater horizontal distance from the observing station.

Developing further the concept that the upper atmospheric airglow layer acts as a screen, upon which the thermospheric neutral wind velocity structures are projected, the DIS has the capability to make Doppler wind measurements not only for each individual FabryPerot fringe, but at a number of individual azimuthal locations around each individual fringe. These individual raw Doppler wind measurements are of the line-ofsight (1-o-s) velocity component resolved onto the viewing direction.

During the data analysis procedure for the DIS instruments at Svalbard and Kiruna, each individual Fabry-Perot fringe is divided into 24 sectors at $15^{\circ}$ intervals. This is done for each of the first six fringes which are imaged, entirely or in part, within the useable area of the ICCD detector. Thus, we determine a matrix of Doppler shifts which can be assigned to many specific locations on the airglow "screen". The direct measure-

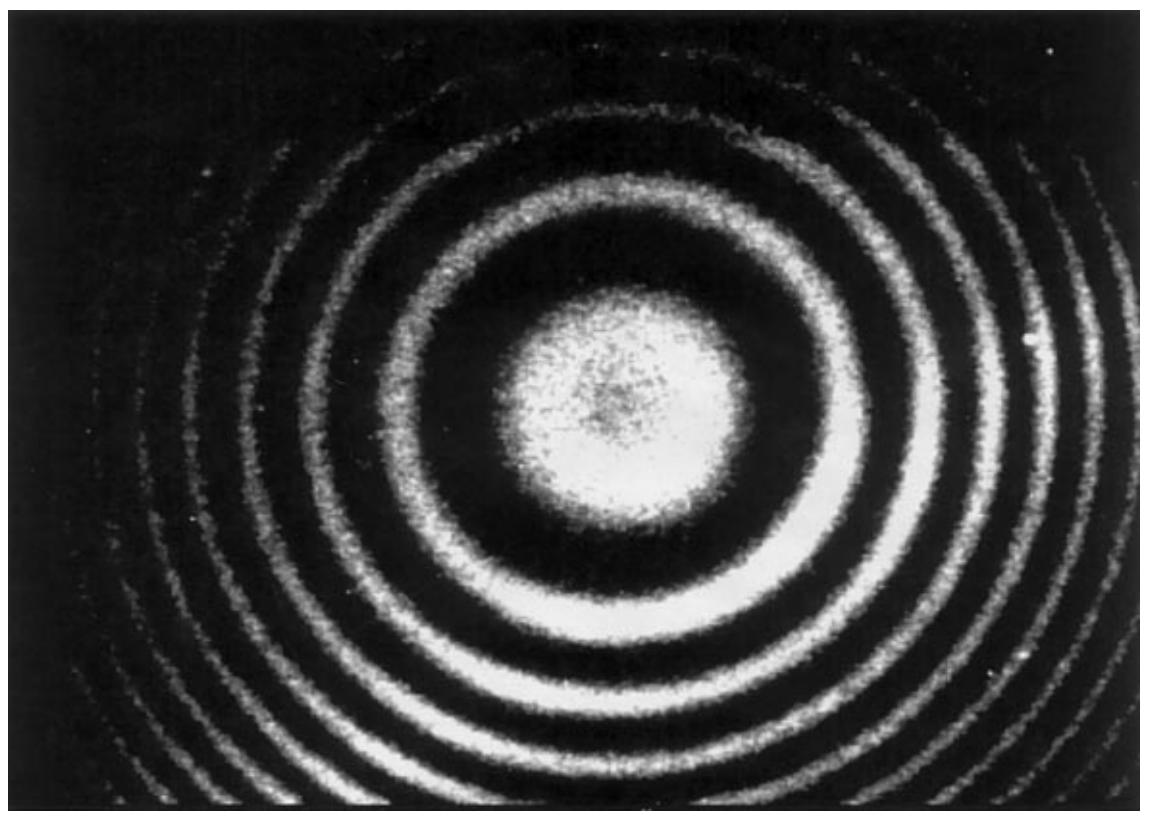

Fig. 1. This illustrates the geometric projection from the far-field screen created by the atomic oxygen airglow layer near $240 \mathrm{~km}$ altitude onto the image plane of the DIS instrument 


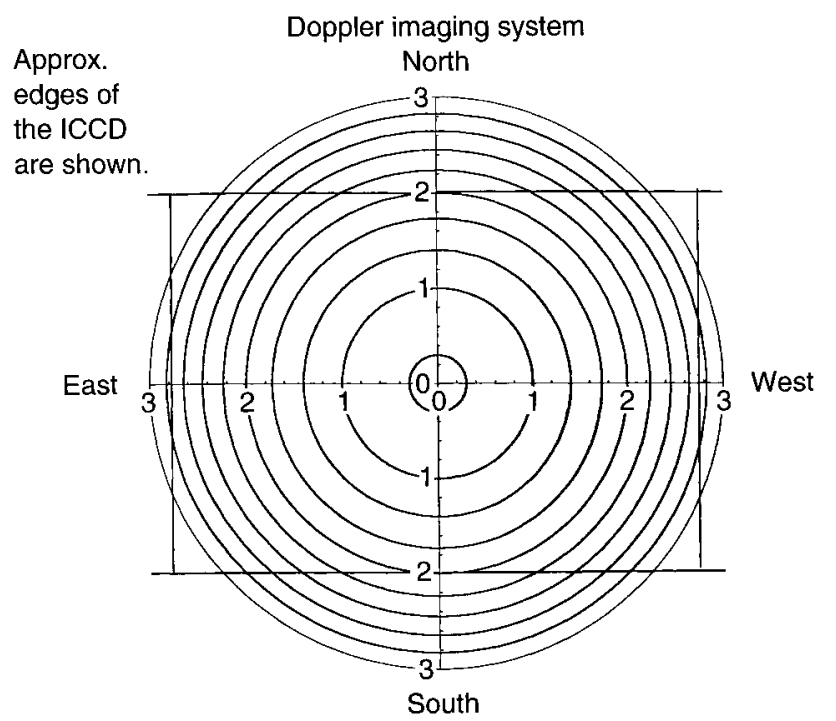

Fig. 2. This displays a single image of the sky taken by the DIS in Svalbard on December 19, 1995

ments which are made are of the 1-o-s wind components, calculated for each individual $(24 * 6)$ measurement of Doppler shift. These 1-o-s wind components have then to be converted into the horizontal winds.

A much more comprehensive description of the calibration and data analysis procedures can be found in Batten et al. (1988) and Rees et al. (1991), who have also discussed methods by which the distribution of wind flow velocity vectors can be recovered throughout the region of approximately $600 * 800 \mathrm{~km}$ diameter which is observed, using the OI $\left({ }^{1} \mathrm{D}-{ }^{3} \mathrm{P}\right)$ emission at $630 \mathrm{~nm}$, given the rectangular geometry of the CCD detector in current use. A brief review of the basic geometrical and mathematical analysis can be found in Appendix 1.

The DIS may thus provide considerable detail of the wind flow patterns and on their spatial and temporal variations, as has been discussed by Batten et al. (1988), Rees et al. (1991, 1997), Biondi et al. (1994) and Nakajima et al. (1995). For further details of the analysis, the interested reader is referred to Batten et al. (1988), Batten (1989) and Rees et al. (1989, 1991, 1997).

The purpose of this study is to describe the thermospheric wind data now available from the DIS Instruments in Svalbard and Kiruna, and the prospects for their use in co-operative investigations with EISCAT. As such, the presentation of the data will be simplified to emphasise the major features of the instruments and their observations.

\section{Data analysis procedures for the Doppler imaging system}

There are two important stages of calibration of the DIS instrument which are required for the data analysis. Since the DIS instrument contains no moving parts, these calibrations will remain valid for long periods, as long as no significant mechanical adjustments are made to the instrument.

\subsection{Geometric calibration of the DIS}

We have to obtain the precise relationship between each point in the focal plane, the azimuth and elevation in the sky, or the corresponding projection onto the assumed "screen" at $240 \mathrm{~km}$ altitude in the upper atmosphere. Since the optical train of the DIS, from all-sky lens to ICCD detector, has moderate complexity, it is not practical to obtain this calibration by pure calculation, with the accuracy necessary for the conversion from 1-o$s$ to horizontal wind component, or for calculation of the horizontal location with respect to the observer.

The most accurate geometric calibration of the field of view can be obtained by removing the narrow-band interference filter. A sequence of many short images of star fields is then taken, with the intensifier set at maximum gain. The short star trails in these images can be used to improve the final focus. These star images also provide a large number of individual points for which the azimuth and elevation can be readily calculated. The "plate constants", as defined in conventional astrometric applications, can then be calculated. Even given the very small effective aperture of the all-sky input camera lens, the ICCD detector is sensitive enough to image stars of second-third magnitude over the entire field of view, providing many independent near-point sources for calibration of each image. The basic equations from which the plate constants are derived, and the astronomical ephemeris calculations, are described in any textbook on classical or positional astronomy.

These data provide a basic calibration of the projection of the detector's image field onto the sky. There is, however, one remaining factor which has to be allowed for. The narrow-band interference filter of the DIS is located in weakly convergent light. The filter has a nonnegligible thickness and, more-over, may be slightly non-orthogonal to the optical axis (to allow angular adjustment to obtain maximum transmission of the OI $630 \mathrm{~nm}$ emission). Thus, the instrument $\mathrm{f}-\mathrm{o}-\mathrm{v}$ is weakly defocused and moved laterally by the interference filter. Unfortunately, with the narrow-band filter in place, it is only possible to image the moon and the very brightest stars and planets. At the high northern latitudes of Kiruna and Svalbard, the brightest stars are never visible, and the brightest planets are only rarely observable within the field of view of the DIS. Given that only Vega and Capella are regularly detectable in the DIS images, sequences of short exposure images of the moon are used to provide an additional matrix of measurements from which the defocus and translation of the DIS images by the filter can be calculated. We should note that accuracies of the order of $0.1^{\circ}$ arc are adequate for calculation of the optical geometry of the DIS.

\subsection{Spectroscopic calibration, including derivation of the "zero wind" Doppler shift}

Compared with a traditional Fabry-Perot interferometer, the spectral calibrations of the DIS are more 
complex, and not only because of the number of individual measurements which are required.

While the DIS has no moving or scanning parts, we require the analysis of Doppler Shift at many points within the image. This is in contrast to the calibration for a single on-axis "point" as is required when using a detector such as a photomultiplier, or the calibration of the imaging Fabry-Perot interferometer which uses a two-axis imaging photon detector (Rees et al., 1989). A scanning mirror, viewing sequentially around the sky, and also viewing a spectral calibration lamp, facilitates the necessary calibrations for both these instruments.

Looking at the problem from a logical point of view, perhaps rather than mathematically, for each sector, of each Fabry-Perot fringe we intend to process (i.e. approximately $24 * 6$ regions) we need to define:

1. The "zero-wind-velocity" baseline;

2. The sensitivity in terms of 1-o-s wind component per unit change of the fit to the Doppler profile;

3. The sensitivity in terms of horizontal wind per unit change of the fit to the Doppler profile;

4. The variations of optical path difference (OPD). Though small, and though the same for the entire spectral image, the changes need to observed and taken into account during the data analysis.

As background calibrations, we also need:

a. A two-dimensional map of the sensitivity of the detector;

b. A two-dimensional map of the thermionic emission or background noise of the detector.

The basic spectral stability of the OPD (4) is monitored by taking periodic images of a neon calibration source. This process monitors changes of the OPD of the etalon, as measured by changes of the radial position of the fringes (in principle, each sector of each of the fringes to be used for analysis).

However, this process, while essential, does not derive the "zero-wind-velocity" baseline for each of the $(24 * 6)$ regions at which we wish to derive Doppler shifts. The process by which this the "zero-windvelocity" baseline is derived for each of the $(24 * 6)$ regions is relatively complex, due to the number of points for which the calculations have to be performed. However, the basis of the computation is as follows.

Since we are dealing with Fabry-Perot fringes, while each fringe is a projection from widely-spread locations over the sky, they can, indeed, be processed as if they were simply fringes from a single source.

The first analysis stage is therefore to process the series of entire fringes $\left(F_{j}\right)$, where " $j$ " runs from 1 to 6 .

1. For the central fringe of the DIS (closest to the zenith), the 1-o-s component in each sector contains a contribution due to the vertical wind, although a significant resolved components of the horizontal wind is also included. Given that the angular diameter of the central fringe, projected onto the sky, may be as much as $10^{\circ}$ arc, in any given sector, as much as $20 \%$ of the horizontal wind may appear in the l-o-s component. Averaging or integrating around the "circle" of the first fringe, these contributions from the horizontal wind (allowing for modest non-homogenities in the horizontal wind field over a horizontal scale of, say, $40 \mathrm{~km}$ and the airglow/auroral intensity) should result in a near-zero average Doppler shift due to the horizontal wind. The mean Doppler shift of this entire first fringe should thus be due to the large resolved component $\left\{\right.$ order $\left.\left(\cos 10^{\circ}\right)\right\}$ of the mean vertical wind, over this region, of up to about $40 \mathrm{~km}$ diameter (within the region of airglow/ auroral emission).

2. The Doppler shift derived from the first fringe will also, however, directly follow any change of OPD of the etalon, from whatever cause. The regular full-field images taken using the neon calibration lamp are thus critically important in determining and removing errors due to any change of the etalon OPD.

3. After correction for changes of OPD, the residual Doppler shift obtained from the entire first fringe may thus be used, to a reasonable degree of accuracy, to estimate the vertical wind in the region about in the zenith, provided that the "zero-wind-velocity" baseline has first been derived for the entire first fringe.

\subsubsection{Derivation of the zero-wind-velocity baseline for the DIS}

Whether for an entire fringe, or for a single sector, this has much in common with the similar problem for a standard or imaging FPI.

1. For periods of heavy cloud, the Doppler shift is greatly reduced due to multiple scattering. Thus, with care, data from many images taken during such cloudy periods, particularly when there is significant auroral enhancement of the OI $630 \mathrm{~nm}$ emission, provide a useful first estimate of the zero-wind-velocity baseline, both for entire fringes, and for each of the 24 sectors within each fringe.

2. Long-term averages (firstly, over one particular night, then for longer periods of many nights) provide an improved estimate, as long as data from nights of particularly strong wind disturbances are removed before taking the averages.

3. Averages, particularly long-term, of the entire first fringe, taken close to the zenith, provide a reasonable estimate of the "zero-wind-velocity" baseline for the first fringe. Similarly, long-term averages taken for each successive entire fringe can be used to estimate the "zero-wind-velocity" baseline for successive fringes.

4. The calibration lamp fringes, though not in an identical location to each of the airglow fringes, are not distorted locally by Doppler shifts. Therefore, these calibration fringes may be used to provide an independent estimate of the "zero-wind-velocity" baseline for each sector of each fringe.

In practice, the analysis of these items is computationally intensive, rather than difficult. A most important feature is the choice of the most appropriate nights from which the zero-wind-velocity baseline can be derived. On the other hand, graphical presentation of 
the respective "differences" from fringe to fringe, from sector to sector and from image to image is straightforward. With modest practice, the selection of appropriate nights which should be included or excluded from within the set of those chosen for the zero-wind-velocity baseline derivation becomes straightforward. Generally, it is necessary to iterate the various stages of the analysis, testing specific images and image sequences.

\section{Wind measurement errors for the DIS}

Wind measurement errors for the DIS are conceptually similar to those for any Fabry-Perot interferometer, with certain complications as the result of the variable geometry for observing the target. There are four basic sources of error in the wind determinations:

1. Statistical errors (dependent on the signal strength, or signal-to-noise ratio);

2. Calibration errors, (primarily determination of the "zero wind velocity" baseline);

3. Geometrical errors, approximations of the viewing angles, altitude uncertainties etc.;

4. Conversion from line-of-sight (l-o-s) to horizontal wind, including assessment of the "vertical wind".

Before the DIS images can be analysed usefully, the "zero wind velocity" baseline must be determined for each sector of each Fabry-Perot fringe. When this has been done the Doppler shift is derived by finding the peak of the fringe, and then taking the difference between the observed peak and the "zero wind velocity" baseline. Without repeating the mathematical details which have been discussed and published by Batten (1988) and Rees et al. (1989), the Doppler shift thus has two sources of uncertainty. Firstly, there is a statistical error which is inversely proportional to the signal-tonoise ratio of the data available for each sector and fringe, and secondly, there is an uncertainty which is dependent on the quality and accuracy of the calibration of the "zero velocity" appropriate to each sector, for each fringe.

\subsection{The zero wind velocity baseline calibration}

The Fabry-Perot etalon is built from two fused-silica optical flats, with three spacers made from zerodur generating and maintaining the optical path difference. The spacers are optically contacted to the etalon plates. The etalon is supported by a cantilever spring mechanism, and the entire unit is enclosed in a sealed container. The sealed etalon container is evacuated, and temperature-controlled to approximately $+\mid-0.1^{\circ} \mathrm{C}$. During observations, the fringe pattern is illuminated by the light from a R-F excited neon calibration lamp $(630.4 \mathrm{~nm})$ on a regular basis, approximately once per $30 \mathrm{~min}$. This calibration process allows the small changes of the optical path difference of the etalon to be monitored regularly, as well as providing an independent monitor of the behaviour of the entire instru- ment and detector. Generally, changes of the optical path difference are observed on a given night corresponding to wind velocities of the order of $5-10 \mathrm{~m} \mathrm{~s}^{-1}$. Occasionally, for example, following breaks in the mains power supply, or other major external transients, larger changes may occur, however, these occur uniformly for the entire instrument, and can be monitored accurately by the regular calibration procedure.

The statistical errors are somewhat more difficult to define in a general sense. While the major source of error in determination of the Doppler shift is associated with the signal quality, the "background" can also have a major effect. For example during periods of strong moonlight, particularly where the image of the moon falls on or close to the sensitive area of the CCD, and more generally in strong twilight, the background may be strongly elevated, and the recovery of an accurate Doppler shift may be compromised.

Generally, the instrument is not run when the sky is above $-8^{\circ}$ depression angle. Compared with the sky brightness during the middle of the night, during twilight, the region of the sky above the setting or rising sun is much brighter. Also, during twilight, there is a strong azimuthal intensity contrast. However, as compensation, there is normally a significant twilight enhancement of the OI airglow intensity above that during the midnight hours (in the absence of an auroral enhancement). Strong moonlight is avoided by an Almanac, which switches the instrument off when the moon is between first and third quarter and close to or within the field of view of the instrument.

If the geometric calibrations of the DIS are performed carefully, then errors from those sources should be negligible.

The dominant sources of wind error for the DIS are therefore:

a. Regions and periods of low airglow/auroral intensity (in this case OI $630 \mathrm{~nm}$ );

b. Dealing with the possible presence of significant vertical winds.

Unfortunately, from an "auroral" station such as Kiruna, a very normal situation is that, during the night time hours, one region of the sky is relatively bright, as the result of auroral enhancement, while another part of the sky displays weak emissions. This is particularly the case during the long winter nights, between 18 UT and 06 UT. Under these conditions, and with a low level of geomagnetic activity, the auroral oval may be located far poleward of Kiruna, the OI emission may be significantly or even strongly enhanced in the north part of the f-o-v of the DIS, while the overhead and southern parts of the sky are characterised by weak "mid-latitude" emissions.

Vertical winds may be estimated, for the region near the zenith, from the analysis of the complete "first fringe". This analysis provides (after correction for OPD changes using the regular neon spectral calibration images) a 6 min resolution in time, and a sensitivity of $5 \mathrm{~m} \mathrm{~s}^{-1}$ for detecting a vertical wind in the region around the zenith. The presence of a vertical wind near 
the zenith does not mean that there is a similar vertical wind throughout the entire region viewed by the DIS. Similarly, the absence of a vertical wind near the zenith does not prove that the entire field of view is free of any regions of significant vertical winds. However, it would be reasonable that, were strong vertical winds inferred from the zenith observations, a cautious approach should be taken to processing the data from DIS images during that and the adjacent period.

In Appendix 2, a series of DIS wind data have been processed to investigate the intrinsic wind errors. The random errors in the individual 1-o-s wind measurements made at $38^{\circ}$ zenith distance (single sector, single fringe) of a single fringe is $5 \mathrm{~m} \mathrm{~s}^{-1}$. This implies a random horizontal wind error value of $10 \mathrm{~m} \mathrm{~s}^{-1}$, which has been taken as the typical wind error for the data sets presented in this work. None of the data sets presented here showed evidence for strong vertical winds (say greater than $25 \mathrm{~m} \mathrm{~s}^{-1}$ ) in the zenith during the periods of observation. This error is not valid for regions of exceptionally weak OI emission, where the individual wind errors may be significantly higher $\left(25 \mathrm{~m} \mathrm{~s}^{-1}\right.$ under worst case conditions)

\section{DIS observations from Svalbard in late 1995}

During the period from early December until late January, Svalbard is within the region of "polar winter night". Optical ground-based observations can be made during this period throughout $24 \mathrm{~h}$, providing a unique view of the day-side polar cusp. On December 19, 1995, the DIS at Adventdalen, Svalbard, was therefore able to observe the thermospheric wind pattern for the entire $24 \mathrm{~h}$. During the period from approximately 02:00 UT until 17:00 UT on December 19, the sky was clear and there was a moderate level of auroral activity over most of the sky throughout the period. Emissions associated with the polar cusp were observed between approximately 06:00 UT and 12:00 UT. The behaviour patterns of the auroral OI $\left({ }^{1} \mathrm{D}-{ }^{3} \mathrm{P}\right)$ emission during this day have been described by Rees et al. (1997). The Fabry-Perot fringe data from each successive DIS image have been processed by a method described by Rees and Greenaway (1983) and Rees et al. (1984 a, b).

Figure 3 shows a two-dimensional display of processed DIS data for 19 December, 1995. The horizontal winds have been derived and displayed for each of the 24 azimuthal sectors of the third Fabry-Perot fringe, for each image obtained during the entire period of observations. This third fringe is at a zenith distance of $38^{\circ}$. When projected onto the thermospheric OI $\left({ }^{1} \mathrm{D}-{ }^{3} \mathrm{P}\right)$ emitting layer, the fringe describes a near-circle, some $200 \mathrm{~km}$ in radius, centred on Adventdalen.

In Fig. 3, the DIS sector number is shown as the vertical axis. This sector number runs from 1 to 24 , corresponding to north (1), east (7), south (13), west (19) and back to north. The horizontal axis is Universal Time during the day. The colour scale is the horizontal wind component, colour-coded by the red (away) or blue (toward) sense of the Doppler shift. Larger winds correspond to more intense colours. The colour contours, contrasting with the colours used to shade the areas, display the actual horizontal wind speeds. In Fig. 3, the maximum "blue shift" is $400 \mathrm{~m} \mathrm{~s}^{-1}$, and a maximum "red shift" is $200 \mathrm{~m} \mathrm{~s}^{-1}$. A convenient way to visualise the wind flow, using these figures, is to identify the region of maximum "blue shift" at any time. Turning to face into this direction, the observer would be facing directly into the direction of peak wind-flow. In normal operation, the DIS takes a complete two-dimensional image of the sky every 300 or $600 \mathrm{~s}$. Even though we have chosen to limit the presentation here to the third Fabry-Perot fringe, all 24 azimuthal data sets are shown in the display in Fig. 3. With the exception of periods and regions of low intensity, the wind variations in

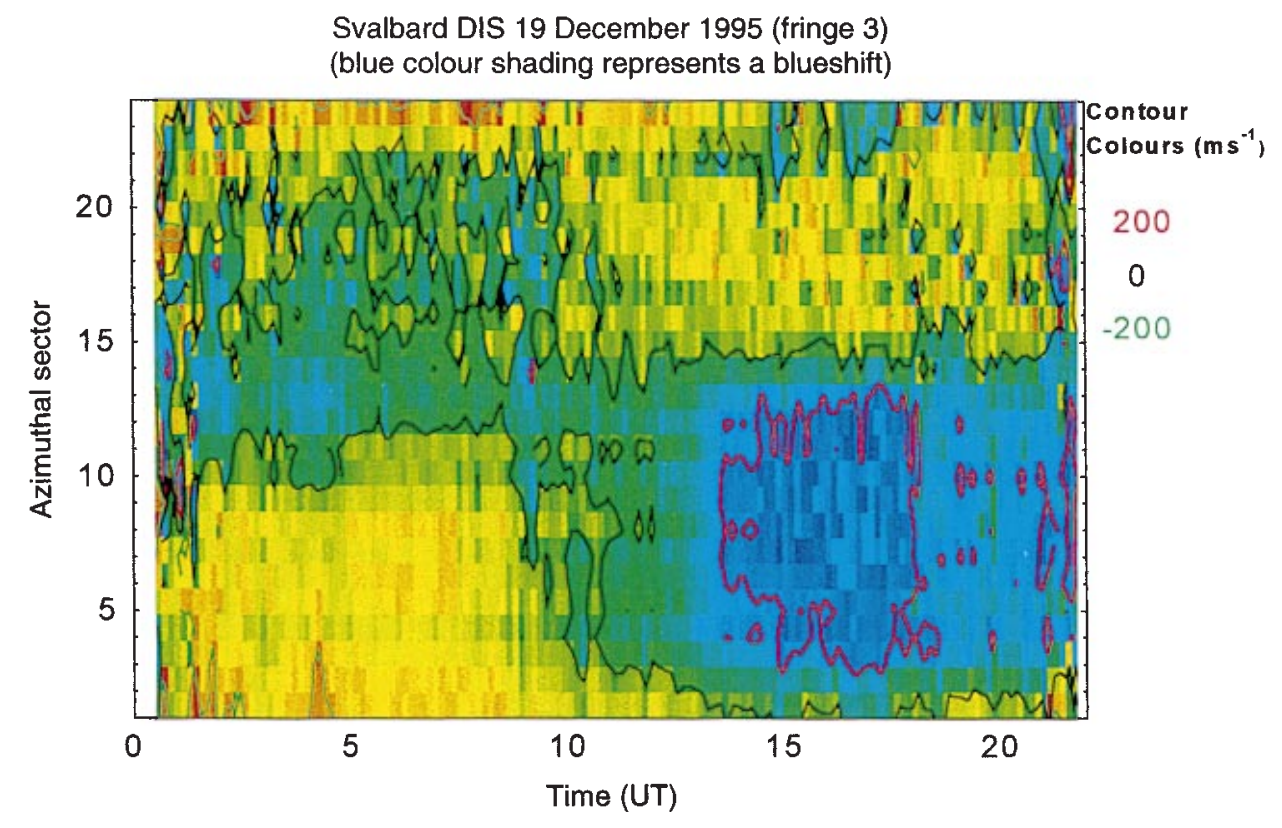

Svalbard DIS 19 December 1995 (fringe 3)

Fig. 3. This shows a two-dimensional display of the processed DIS data for December 19, 1995 
azimuth and in time are generally continuous, indicating that the individual wind measurement errors are indeed small compared with the average thermospheric wind components, which are of the order of $100-200 \mathrm{~m} \mathrm{~s}^{-1}$.

Before magnetic noon on December 19, the atomic oxygen emission was Doppler shifted to the red in the east and north parts of the sky, while the south and west parts of the sky show a blue Doppler shift (green, in this display). The demarcation between blue and red shifts is shown by the black zero-velocity contour. Thus, in the morning period, there is a predominant eastward wind, with an additional northward (poleward) component. After approximately 10:00 UT (just after local magnetic noon) the wind pattern changed rapidly, with red Doppler shifts in the west and blue Doppler shifts in the east, thus indicating that the horizontal wind was westward throughout the rest of the period of observations. Toward midnight UT, the intensity of the OI $\left({ }^{1} \mathrm{D}-{ }^{3} \mathrm{P}\right)$ emission became very weak.

Figure 4 shows the horizontal winds corresponding to the individual north and south (Fig. 4a) and west and east (Fig. 4b) viewing directions respectively. Before

Svalbard DIS: Horizontal velocity components for north/south sectors throughout 19 December 1995 (fringe 3)

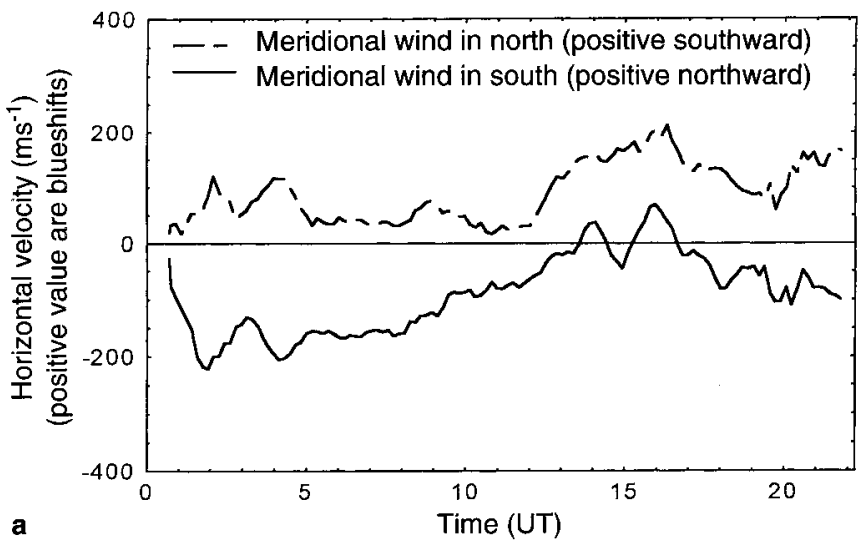

Svalbard DIS: Horizontal velocity components for east/west sectors throughout 19 December 1995 (fringe 3)

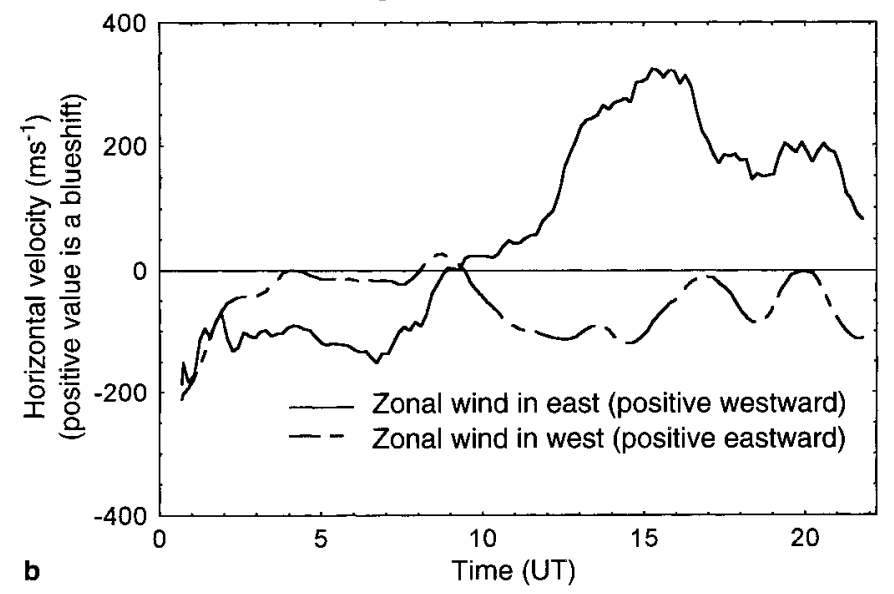

Fig. 4a, b. This shows the horizontal winds corresponding to the individual north and south (Fig. 4a) and west and east (Fig. 4b) viewing directions, respectively approximately 10:00 UT, viewing to both the east and to the west, the thermospheric wind was eastward, changing to westward after 11:00 UT, confirming the overall impression provided by Fig. 3. The diurnal variation of the neutral wind flow on December 19, 1995 thus corresponds to the average diurnal variation of the zonal ion flow in the vicinity of the auroral oval/polar cusp. Thus it is reasonable to associate the neutral winds, and wind flow variations, with Lorentz forcing (ion drag) created by the ionospheric plasma flows.

Were the thermospheric wind field entirely uniform, we would expect that the winds in the north and south, and those in the east and west, would be symmetric. However, the horizontal separation between these viewing directions is $400 \mathrm{~km}$. Both in the meridional, and in the zonal directions, it would be expected that considerable differences between the wind behaviour should occur. For example, in the mid-day period, the south direction is generally equatorward of the polar cusp, while the "north" direction is generally poleward of the cusp.

This mode of ion-neutral momentum coupling may be enhanced by the combination of two processes, both of which increase the F-region electron density and thus increase the Lorentz forcing. Firstly, fluxes of low energy electrons are known to be an important component of precipitation in the vicinity of the dayside polar cusp. These soft electrons penetrate to F-region, but not E-region altitudes, locally enhancing the F-region plasma density. Secondly, even at the winter solstice, the solar depression angle is about $12^{\circ}$ at "mid-day". Thus, for a few hours around mid-day, the sun illuminates the " $F$ " region and causes additional photo-ionisation of the F-region ionosphere. Throughout the period of observations on December 19, the DIS showed that there was a weak poleward wind of the order $100 \mathrm{~m} \mathrm{~s}^{-1}$.

\section{DIS observations from Kiruna in early 1997}

During early 1997, the DIS located at IRF, Kiruna, observed the thermospheric response to two periods of disturbed geomagnetic conditions. The period of January $10-11,1997$, was a minor geomagnetic storm, which is the subject of an intensive co-ordinated study, due to the wealth of space-based and ground-based data available for the period. The peak geomagnetic activity between, approximately 12:00 UT and 13:00 UT, occurred during daylight hours in the European sector. Early in the evening (15:00 UT until 17:00 UT), the DIS observed a series of strong arcs in the OI $\left({ }^{1} \mathrm{D}^{3} \mathrm{P}\right)$ emission at $630 \mathrm{~nm}$ to the north of Kiruna, associated with the period of strongest north-westward winds. This event was also observed by the Swedish ALIS system (Brandstrom et al., 1997) and is the subject of an ongoing combined data analysis.

Figure 5 summarises the thermospheric wind behaviour above Kiruna during the evening of January 10 and the early morning of January 11, 1997. Figure 6 shows the horizontal winds corresponding to the individual north and south (Fig. 6a) and west and east (Fig. 6b) 
Kiruna DIS for period covering the evening of 10 January and the morning of 11 January 1997 (fringe 3) (blue colours on image correspond to blueshift)

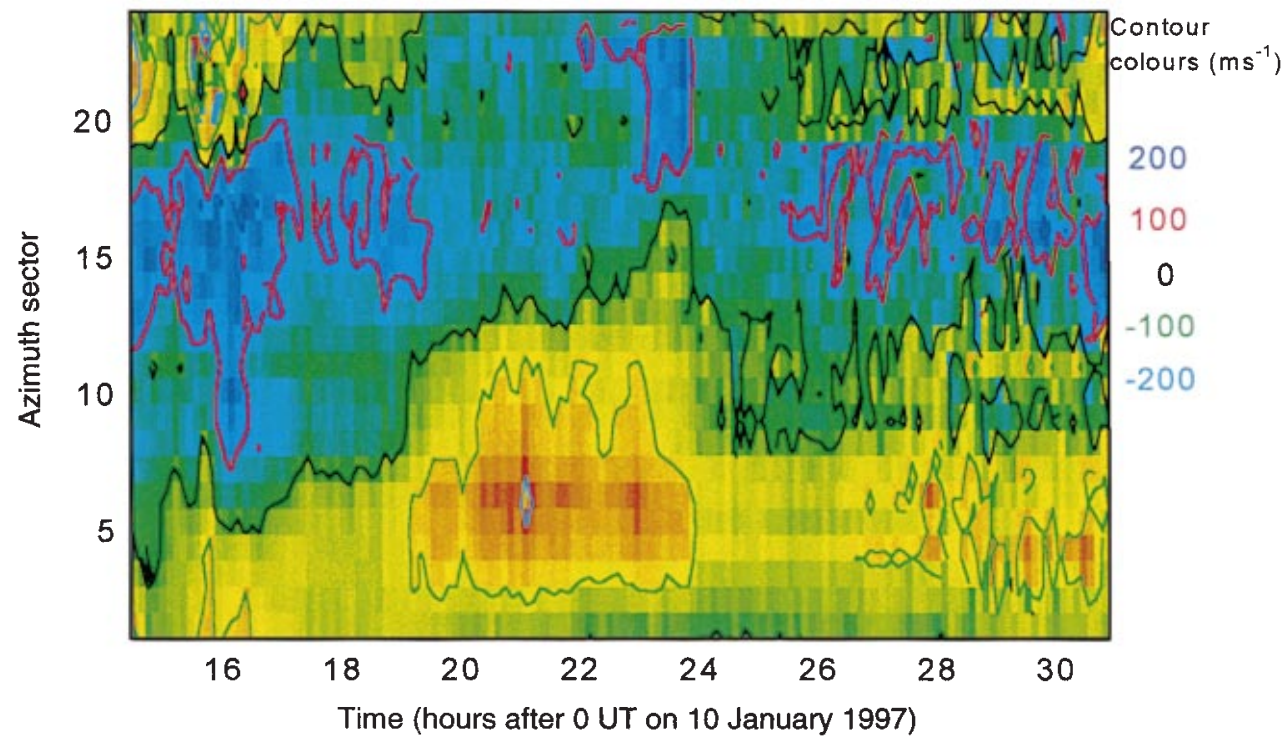

Fig. 5. A summary of the thermospheric wind behaviour above Kiruna during the evening of January 10 and the early morning of January 11, 1997 viewing directions, respectively, above Kiruna during the evening of January 10 and the early morning of January 11, 1997.

Despite the strong geomagnetic activity, as little as three hours before DIS observations started at Kiruna, the peak thermospheric winds observed by DIS were only around 200-300 $\mathrm{m} \mathrm{s}^{-1}$. Between 15:00 UT and 17:00 UT, the contours show a general northward wind flow $\left(200 \mathrm{~m} \mathrm{~s}^{-1}\right)$, but with westward wind components of $200 \mathrm{~m} \mathrm{~s}^{-1}$ to the west and northwest of Kiruna. During disturbed periods such as January 10/11, we should anticipate a significant amount of spatial variability within the $400 \mathrm{~km}$ diameter region displayed in Fig. 5. In contrast, however, on December 12, 1981, at the peak of a similarly strong geomagnetic disturbance, the FPI at Kiruna observed westward winds as high as $900 \mathrm{~m} \mathrm{~s}^{-1}$ (Rees et al., 1985).

Between 17:00 UT and 20:00 UT, following the zero velocity contour (black line), the wind vector rotated from northwestward through northward, northeastward, and became strongly eastward until the early morning hours of January 11 . The zonal wind direction showed a variation from approximately northwestward early in the period of observations (up to around 17:00 UT), followed by a gradual change in direction to eastward after 19:30 UT. This corresponds, approximately, to the expected wind variations during the night, assuming that the primary cause of the zonal wind variations was ion drag generated by the flow of ionospheric plasma within the auroral oval (FullerRowell et al., 1988). However, the meridional wind departed from the average behaviour, as described by Rees et al. (1985), in that during the late evening hours and midnight hours, the wind vector did not turn strongly equatorward (southward).

The third event which will be described is the disturbed period observed from Kiruna on the night of
February 8 and early morning of February 9, 1997. Figure 7 shows the overall wind flow during this night, while Fig. 8 (a, b) shows, respectively, the individual meridional and zonal wind components for the north and south and the east and west viewing directions, for the night of February 8/9 1997. At the start of observations in the early evening, the wind was westward, somewhat similar in direction to that on January 10, 1997, but with a lower maximum westward wind velocity. Between 16:00 UT and approximately 20:30 UT (which corresponds approximately to the mean time that the Harang discontinuity passes over Kiruna), the wind vector rotated steadily from westward to southward. After a brief period in the early morning hours of February 9 when the quality of the Fabry-Perot fringes was poor, the wind vector rotated back to westward, with variable wind magnitude after midnight UT.

The westward thermospheric wind in the early evening of February 8 was most probably caused by Lorentz forcing (ion drag) due to the strong sunward ion convection within the evening auroral oval (Rees et al., 1985). Later in the evening hours, the wind vector rotated from westward to southward. The southward (equatorward) flow during the night-time hours was due to the anti-Sunward wind flow over the geomagnetic polar cap from the dayside sub-solar region of generally higher thermospheric temperature and pressure. This was augmented by pressure gradients induced by heating due to particle and Joule heating within the polar cap and auroral oval.

The thermosphere above northern Scandinavia was subject to unusually close scrutiny during the night of February 8 and the morning of February 9, 1997. Generally clear skies throughout this geomagnetically disturbed period allowed observations from the DIS at Kiruna to be augmented by measurements from the conventional scanning Fabry-Perot interferometers at 
Kiruna DIS: Horizontal velocity components for north/soutt sectors during the evening of 10 January and the morning of 11 January 1997 (fringe 3)

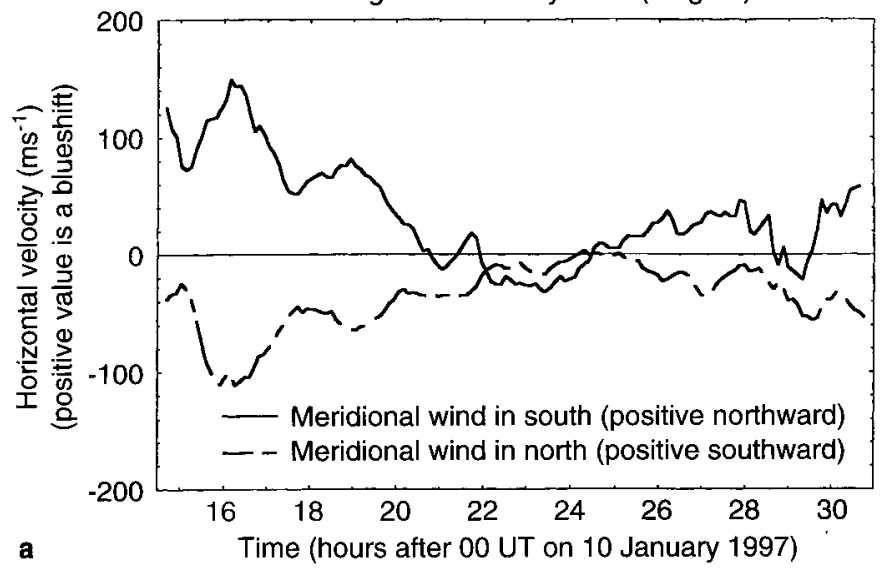

Kiruna DIS: Horizontal velocity components for east/west sectors during the evening of 10 January and the morning of 11 January 1997 (fringe 3)

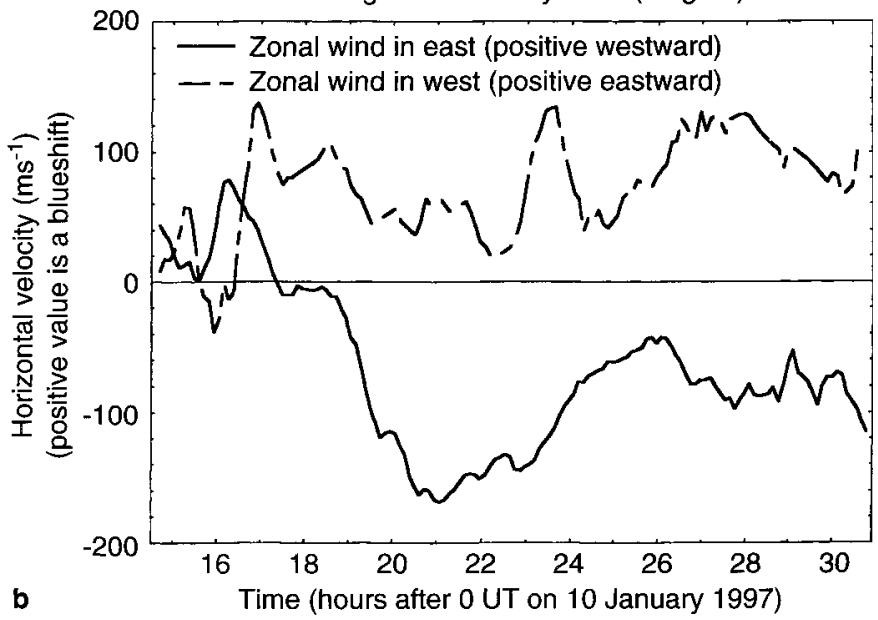

Fig. 6a, b. The horizontal winds corresponding to the individual a north and south, and $\mathbf{b}$ west and east viewing directions, above Kiruna during the evening of January 10 and the early morning of January 11, 1997

Andoya (the ALOMAR Observatory), EISCAT (Ramfjord, Ishii, private communication, 1997) and Skibotn (Kosch et al., 1997a, b), and a further DIS at EISCAT (Ramfjord, Ishii et al., 1997).

The data sets from these various instruments have, as yet, only been subject to a preliminary analysis. Multistation coverage of this geomagnetically disturbed period will allow a series of interesting comparisons, as well as an intensive multi-station investigation of the thermospheric response.

These periods of elevated geomagnetic activity have recently the subject of intensive numerical modelling studies (Buonsanto and Fuller-Rowell, 1997; Rees et al., 1998), taking advantage of the availability of global data from the ISTP Spacecraft, in addition to that from ground-based instruments. A preliminary comparison with the results of a numerical simulation will be presented and discussed here, although comprehensive comparisons with numerical simulations will be left to a future paper (Rees et al., 1998). By means of such joint studies, we have the possibility of unraveling the causes of the observed wind patterns, examining the roles of the major driving forces, Lorentz forcing due to the electric field, pressure gradients induced by particle and Joule heating, and the effects of their complex time-dependent changes.

\section{Comparison with a numerical simulation by a coupled thermosphere-ionosphere - plasmasphere model (CTIP-200)}

"CTIP-200" is the latest production version of a fullycoupled three-dimensional, time-dependent global numerical model of the thermosphere-ionosphere-plasmasphere. The CTIP-200 model is based on the original "UCL" thermospheric and "Sheffield" ionospheric codes originally developed in the early 1980s. FullerRowell and Rees (1980) and Quegan et al. (1982) describe, respectively, the origins of the thermospheric and ionospheric models, while Fuller-Rowell et al. (1996) and Millward et al. (1996), and references therein, have described the recent development of the model, leading to the current CTIP-200 formulation.

The CTIP model contains three specific components:

a. A global thermospheric model;

b. A high-latitude ionospheric model;

c. A mid- and low-latitude ionospheric/plasmaspheric model.

Each of these models are non-linear, and fully-coupled with respect to energy, momentum and continuity. The lower boundary of the model is at $80 \mathrm{~km}$ altitude, where the conditions, apart from tidal forcing, are fixed and constant as a function of time, latitude and season. The model's variable inputs include a description of solar UV/EUV heating and photo-ionisation, corresponding to the appropriate solar activity (keyed by the $\mathrm{F}_{10.7} \mathrm{~cm}$ solar flux) ionospheric plasma convection in the form of a polar convection pattern and a low-mid-latitude ionospheric drift model, and high-latitude energetic electron precipitation. Several alternative models for high-latitude convection and precipitation can be used for the purposes of specific global simulations. The model has a latitude grid of $2^{\circ}$, and a longitude grid of $18^{\circ}$, there are 15 steps in pressure. The upper boundary corresponds approximately to the exobase. The normal time step is $1 \mathrm{~min}$ (decreased where necessary to avoid advective instabilities).

The CTIP-200 version code used for these simulations has been run, under UNIX, on a DEC-Alpha workstation (4/200) with $192 \mathrm{MB}$ of core memory. This machine requires approximately $6 \mathrm{~h}$ of $\mathrm{CPU}$ time to compute $24 \mathrm{~h}$ of UT.

For the simulation of the January 10/11 1997 disturbance, the auroral energy input was taken from the NOAA/TIROS power index. While for many of the simulations generated with the CTIP-200 model, the polar electric field distribution has been obtained by scaling to the NOAA/TIROS power index, as described 


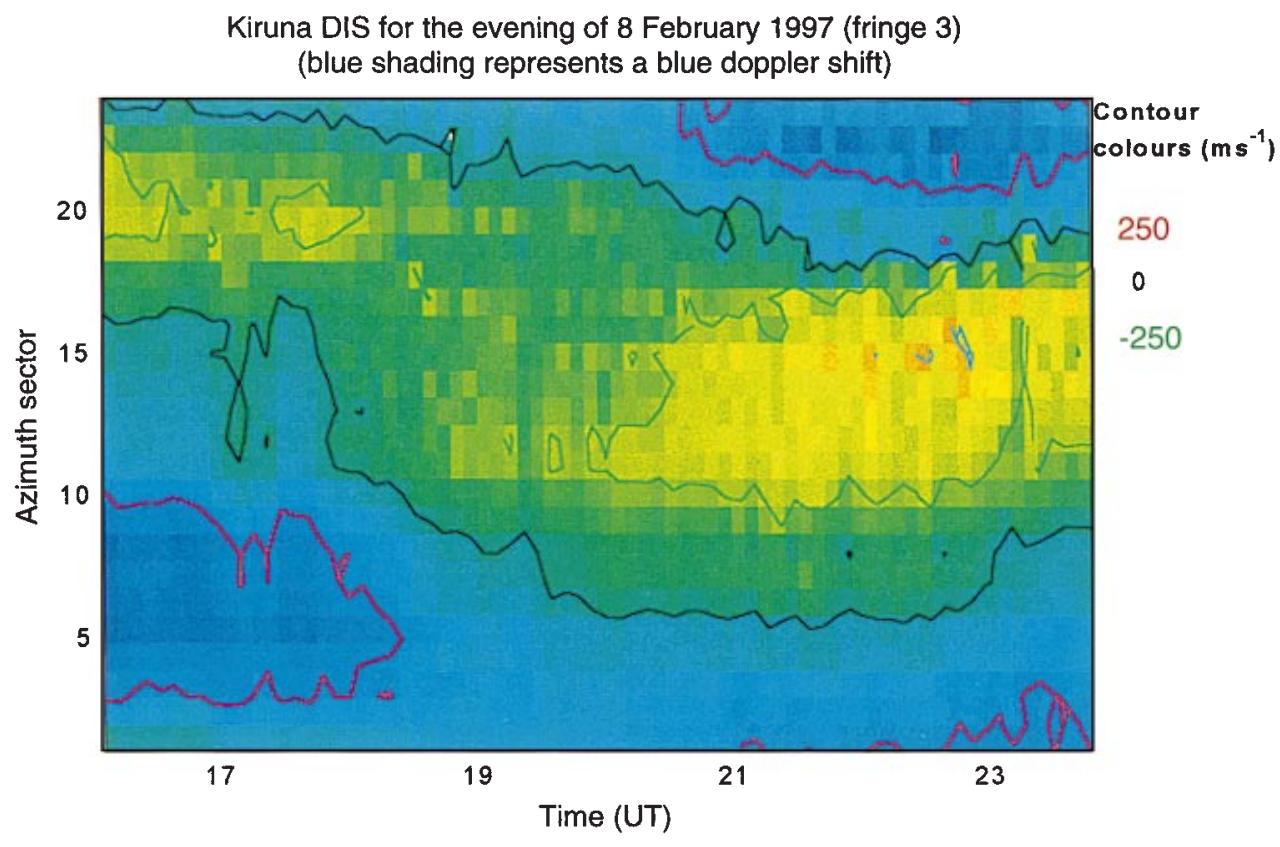

Fig. 7 Thermospheric wind behaviour above Kiruna during the night of February 8/9 1997
Kiruna DIS: Horizontal velocity components for north/south sectors throughout the evening of 8 February and morning of 9 February 1997 (fringe 3)

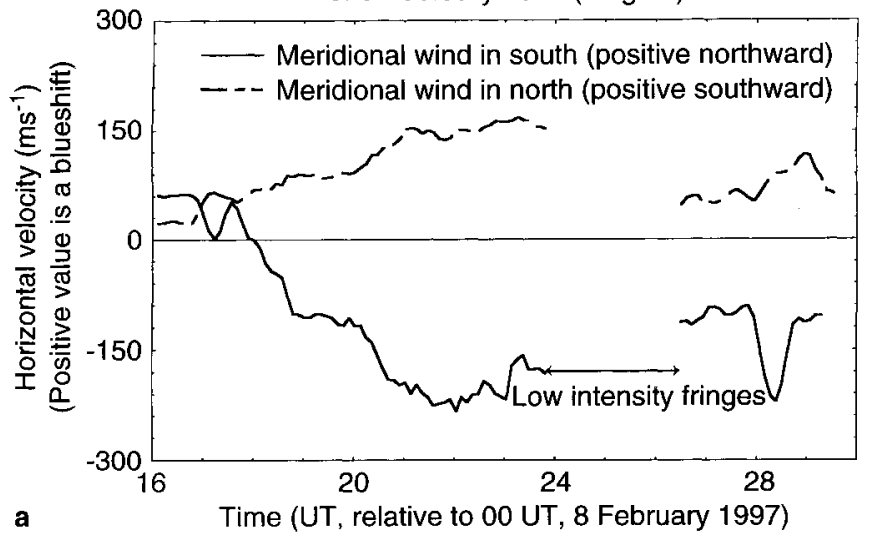

Kiruna DIS: Horizontal velocity components for east/west sectors throughout the evening of 8 February and the morning of 9 February 1997 (fringe 3)

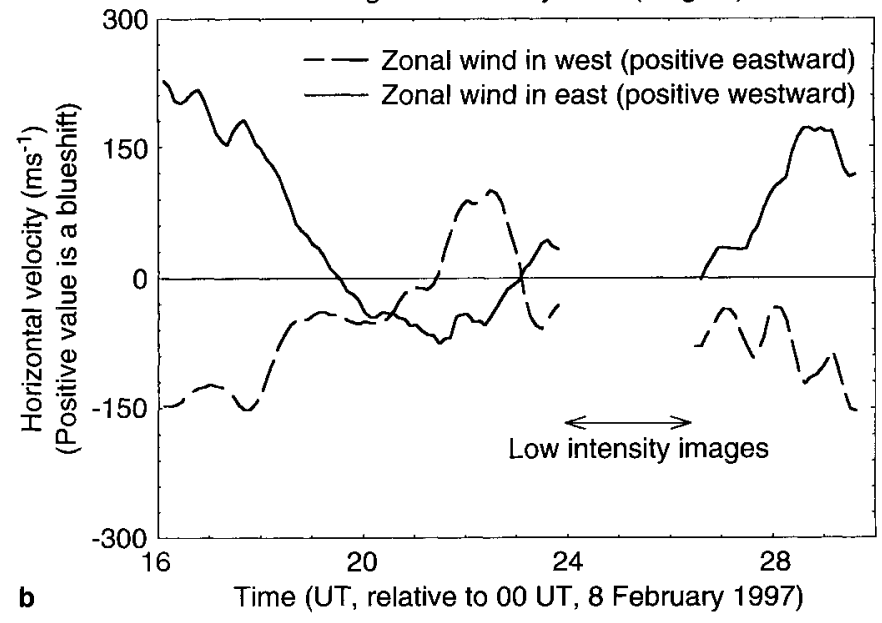

Fig. 8a, b. The horizontal winds corresponding to the individual a north and south and $\mathbf{b}$ west and east viewing directions, above Kiruna for the night of February 8/9 1997 by Fuller-Rowell and Evans (1985), for this simulation, the time-dependent polar electric potential was derived from the "AMIE" technique, as described by Richmond and Kamide (1988). The method by which this timedependent polar potential has been introduced to the CTIP-200 model has been described by Rees et al. (1998)

Figure $9 \mathrm{a}, \mathrm{b}$ displays the variations of the meridional and zonal wind components respectively, as a function of Universal Time, for the thermosphere (pressure level 13, approximately $240 \mathrm{~km}$ altitude) above Kiruna, taken from the time-dependent simulation by the CTIP-200 model of the disturbed period January 10 and 11 . Wind data are shown for the complete 24 hours of January 10.

The meridional wind simulated for January 10 by CTIP-200 shows many of the same features as the DIS wind measurements:

1. In the early evening hours, the simulated meridional wind is northward before 15 UT, then becomes southward, increasing after 19 UT to a maximum value between 120 and $150 \mathrm{~m} \mathrm{~s}^{-1}$.

2. The meridional wind observed by the DIS (Fig. 6) to the south and to the north of Kiruna is northward until 20 UT, after which time it turns southward, but with values of less than $50 \mathrm{~m} \mathrm{~s}^{-1}$. The trend in the meridional wind is similar in both model and observation, however, the observed winds are systematically more northward, or less southward, than in the model.

The simulated zonal wind shows significantly better agreement with the DIS wind measurements:

1. The simulated zonal wind is westward before $16 \mathrm{UT}$.

2. Around 20 UT, the simulated zonal wind direction changes to eastward, a direction which is sustained for the rest of the night.

3. The zonal wind observed by the DIS shows very similar behaviour as regards direction. 

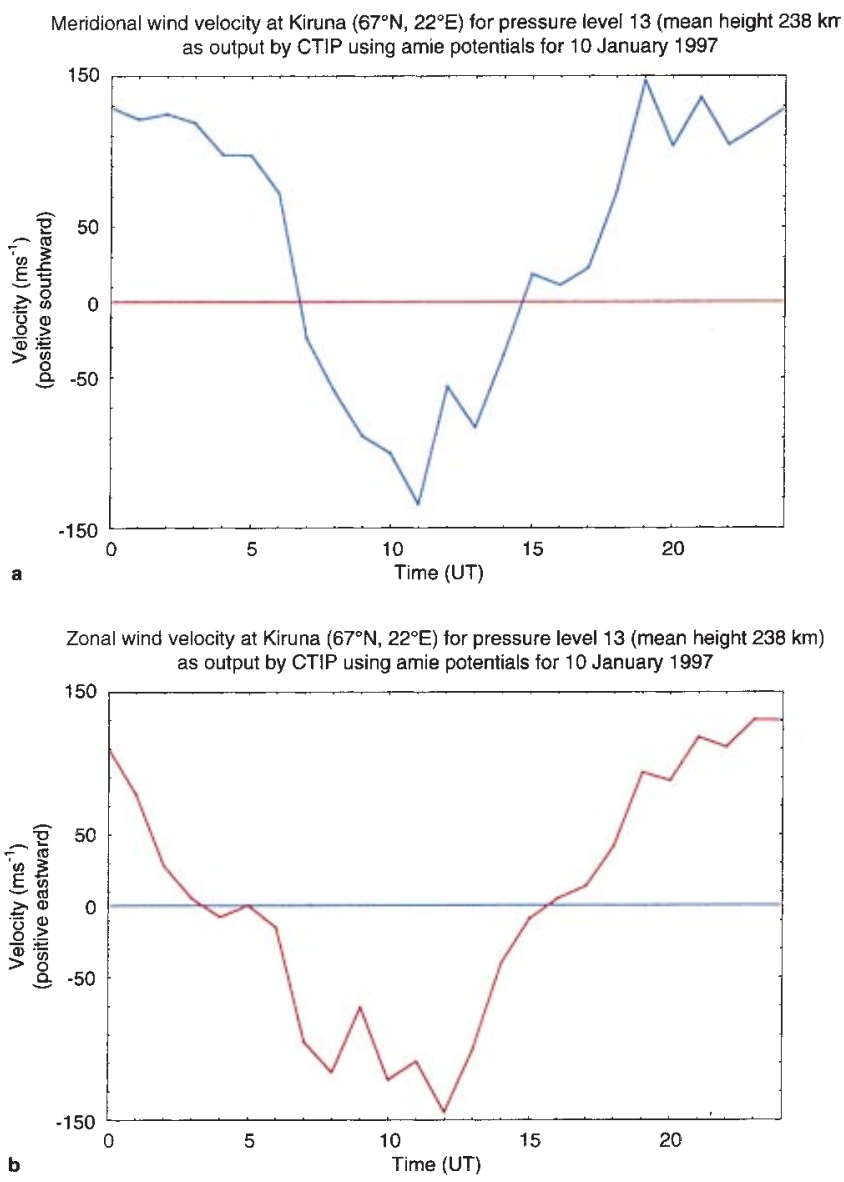

Fig. 9a, b. The variation of the meridional and zonal wind in the upper thermosphere during January 10 1997, simulated by the CTIP200 global numerical model

4. Peak values of the observed eastward winds after 20 UT were around $100-150 \mathrm{~m} \mathrm{~s}^{-1}$, very similar to those in the simulation $\left(120-150 \mathrm{~m} \mathrm{~s}^{-1}\right)$.

The agreement between the zonal wind time variations and velocities between the CTIP-200 numerical model and the DIS observations implies that we can, for example, attribute the weak westward winds observed before 17 UT to ion drag acceleration within an enhanced and expanded dusk auroral oval. The simulation indicates that, due to daylight and twilight, we were unable to observe the period when strongest westward winds (at the time of greatest geomagnetic activity) probably occurred, between around 8 and 13 UT.

The disagreement between the absolute values of the observed and simulated meridional wind, despite the similarities in the meridional wind trends, is not yet understood. During the period between 10 UT and 13 UT on January 10, the energy input (combined energy of precipitating electrons and from elevated Joule heating) from this geomagnetic disturbance increased suddenly, and to relatively high values. It is possible that the simulation underestimated the maximum total energy input within this period and within the polar and auroral regions. If this was the situation, the simulation would have under-estimated the outflow from high to low latitudes, generated by the disturbance.

By the time the DIS observations were available, during the recovery period, it might be that the meridional wind observations reflect a relative backflow, at the lower level of high latitude energy input.

This topic is discussed further by Rees et al. (1998).

\section{Summary}

Data from the Doppler imaging systems located at Adventdalen, Svalbard, and the IRF, Kiruna, Sweden, from the period since late 1995 have been presented. These include the minor geomagnetic storm of January $10 / 11$ and further geomagnetic disturbances in early February 1997. The DIS data presented here show features of the thermospheric wind which are consistent with the effects of Lorentz forcing (ion drag) driven by the variable magnetospheric electric field, combined with particle and Joule heating.

A preliminary comparison between the thermospheric wind data from the DIS during the disturbed periods of January 10 and a time-dependent numerical simulation keyed to the high-latitude electron precipitation (NOAA/TIROS power index) and cross-polar cap electric fields shows a good agreement between simulated and observed zonal wind magnitude and direction during the night-time hours. For the meridional wind, the simulated and observed trends are similar, but the observed wind is of order $100 \mathrm{~m} \mathrm{~s}^{-1}$ more northward than the simulation. A more detailed simulation and comparison for the January 10/11 minor geomagnetic storm period will be presented and discussed in a future publication.

DIS instruments located at Nordlysstasjonen, and at IRF, Kiruna, Sweden, have been in regular automated operation throughout the winter months since late 1995. Joint studies with the new EISCAT-Svalbard radar and the multi-station FPI/DIS network in northern Scandinavia are planned to make detailed investigations of the energetics and dynamics of the thermosphere and ionosphere within the auroral and polar regions. Further joint studies between data from the DIS and that from complementary instruments in the northern Scandinavian region are in progress and will be reported in due course.

Acknowledgements. Topical Editor D. Alcayde' thanks G. G. Shepherd and another referee for their help in evaluating this paper.

\section{References}

Batten S. The measurement of neutral winds in the thermosphere using a doppler imaging system, thesis presented for $\mathrm{PhD}$, the University of London

Batten S., D. Rees, D. Wade, and A. Steen, Observations of thermospheric neutral winds by the UCL Doppler Imaging System at Kiruna in Northern Scandinavia, J. Atmos. Terr. Phys., 50, 861, 1988. 
Biondi M., M. E. Zipf, D. P. Sipler, and J. L. Baumgardner, ASDI (all-sky Doppler interferometer)-determinations of thermospheric wind and temperature fields over large regions of the upper atmosphere, SPIE, June 1994.

Buonsanto M. J., and T. J. Fuller-Rowell, Strides made in understanding space weather at Earth, EOS, 78, (1) AGU. 1997

Brandstrom, U., A. Steen, B. Gustavsson, D. Rees, and M. Harris, Preliminary results from a comparison of observations of thermospheric neutral wind patterns and auroral emissions, The 24th Annual European Meeting on Atmosphere studies by optical methods ISBN 82-994583-0-7. August 1997.

Fuller-Rowell T. J., and D. Rees, A three-dimensional, timedependent, global model of the thermosphere, J. Atmos. Sci. 37, (11), 2545-67, 1980.

Fuller-Rowell T. J., D. Rees, S. Quegan, R. J. Moffett, and G. J. Bailey, Simulations of the seasonal and universal time variations of the high-latitude thermosphere and ionosphere using a coupled, three dimensional, model, PAGEOPH, 127, (2/3), 187217, 1988.

Fuller-Rowell T. J., D. Rees, S. Quegan, R. J. Moffett, M. V. Codrescu, and G. H. Millward, A coupled thermosphere-ionosphere model (CTIM), STEP handbook of ionospheric models, Ed. R. W. SCHUNK, pp 217-238, SCOSTEP, NOAA/NGDC, 1996.

Ishii, M., S. Nozawa, and S. Ohyama, Spatial and temporal variations of winds in the lower thermosphere near auroral arcs-preliminary results, IAGA Conference in Uppsala, August, 1997.

Kosch, M., T. Haggfors, and D. Rees, A new Fabry-Perot interferometer for atmospheric studies with the EISCAT incoherent scatter radar, Adv. Sp. Res., 20, (6) 1133-1136, Ed. Lastovicka et al., Pergamon, 1997.

Kosch, M., T. Haggfors, and D. Rees, Bi-static observations of horizontal thermospheric neutral winds over northern Scandinavia using ground-based Fabry-Perot interferometers, IAGA Symposium in Uppsala, 1997a.

Kosch, M., T. Haggfors, M. Ishii, and D. Rees, Multi-station measurements of thermospheric vertical winds over northern Scandinavia using ground-based Fabry-Perot interferometers, IAGA Symposium in Uppsala, 1997b.

Millward G., S. Quegan, R. J. Moffett, and T. J. Fuller-Rowell, A coupled thermosphere-ionosphere-plasmasphere model (CTIP), STEP Handbook of Ionospheric Models, Ed. R. W. SCHUNK, pp 239-280, SCOSTEP, NOAA/NGDC, 1996.

Nakajima, H., S. Okano, H. Fukunishi, and T. Ono, Observations of thermospheric wind velocities and temperatures by the use of a Fabry-Perot Doppler imaging system at Swoya Station Antarctica, Appl. Optics 34, (36), 8382-8395, 1995

Quegan S., G. J. Bailey, R. J. Moffett, R. A. Heelis, T. J. FullerRowell, D. Rees, and R. W. Spiro, A theoretical study of the distribution of ionisation in the high-latitude ionosphere and the plasmasphere: first results on the mid-latitude trough and the light-ion trough, J. Atmos. Terr. Phys. 44, 619-640, 1982.

Rees D., Observations and modelling of ionospheric and thermospheric disturbances during major geomagnetic storms: a review, J. Atmos. Terr. Phys., 57, 12, 1433-1457, 1996.

Rees D., and A. H. Greenaway, Doppler imaging system: an optical device for measuring vector winds: 1: general principles, Appl. Opt. 22, 1078, 1983.

Rees D., M. F. Smith, and R. Gordon, The generation of vertical thermospheric winds and gravity waves at auroral latitudes-II. Theory and numerical modelling of vertical winds, Planet Space Sci. 32, 685-705, 1984a.

Rees D., R. W. Smith, P. J. Charleton, F. G. McCormac, N. Lloyd and A. Steen, The generation of vertical thermospheric winds and gravity waves at auroral latitudes-I. Observations of vertical winds, Planet Space Sci. 32, 667-684, 1984b.

Rees D., T. J. Fuller-Rowell, M. F. Smith, R. Gordon, T. L. Killeen, P. B. Hays, N. W. Spencer, L. Wharton and N. C. Maynard, The westward thermospheric jet-stream of the evening auroral oval, Planet. Space Sci. 33, 425-456, 1985.
Rees D., I. McWhirter, A. Aruliah, and S. Batten, Upper atmospheric wind and temperature measurements using imaging Fabry-Perot interferometers, WITS Handbook, 2, 188-223, SCOSTEP, University of Illinois, ed. C. H. Liu, 1989.

Rees D., S. Batten, A. L. Aruliah, T.J. Fuller-Rowell, A. D. Farmer, and K. S. C. Freeman, Long-lived polar thermospheric vortices: a combined radar and optical study, J. Atmos. Terr. Phys., 53, 493-514, 1991.

Rees D., R. W. Smith, F. Signernes, K. Henriksen, N. D. Lloyd and M. Harris, Observations of thermospheric wind patterns in the vicinity of the polar cusp from a Doppler imaging system, $A d v$. Sp. Res., 20, (6) 1129-1132, 1997

Rees D., T. J. Fuller-Rowell, Gang-Lu, G. Millward, D. Iddenden, and G. Maskell, Comparison of the response of the global thermosphere and ionosphere to time-dependent forcing simulations of the January 10/11th 1997 "Minor Storm", (1998) COSPAR 1998, Nagoya, Japan, Adv. Space Res, (in press) 1998.

Richmond A. D., and Y. Kamide, Mapping electrodynamic features of the high-latitude ionosphere from localized observations: technique, J. Geophys. Res., 93, A6, 5741-5759, 1988.

\section{Appendix 1: the mathematical and geometrical principles of DIS data analysis}

The Doppler imaging system measures only a set of lineof-sight (los) components of the mean wind within the airglow layer. To illustrate the initial analysis (Fig. 10), we will assume that, at each measurement point $(\mathbf{i}, \mathbf{j})$, the vertical wind $\left\{\mathbf{V}_{\mathbf{z}}(\mathbf{i}, \mathbf{j})\right\}$ is negligible compared with the horizontal wind $\left\{\mathbf{V}_{\mathbf{h}}(\mathbf{i}, \mathbf{j})\right\}$.

Derivation of the horizontal wind component from the line-of-sight wind component

The horizontal wind component which the DIS can measure on a given fringe (i) and at a given azimuth (j), is given by:

$\mathbf{W}(\mathbf{i}, \mathbf{j})=\mathbf{v}_{\mathbf{h}}(\mathbf{i}, \mathbf{j}) \cdot \cos (\theta-\phi)$

where

$\mathbf{W}(\mathbf{i}, \mathbf{j})=$ the line-of-sight velocity component;

$\mathbf{V}_{\mathbf{h}}(\mathbf{i}, \mathbf{j})=$ total (horizontal) wind velocity;

$\theta=$ observing direction of the DIS (in the horizontal plane);

$\phi=$ bearing of the wind vector (in the horizontal plane);

$$
\text { Thus } \begin{aligned}
\mathbf{W}(\mathbf{i}, \mathbf{j})= & \mathbf{V}_{\mathbf{h}}(\mathbf{i}, \mathbf{j}) \cdot \cos \theta \cdot \cos \phi \\
& +\mathbf{V}_{\mathbf{h}}(\mathbf{i}, \mathbf{j}) \cdot \sin \theta \cdot \sin \phi
\end{aligned}
$$

The Doppler imaging system actually measures the component of $\mathbf{W}(\mathbf{i}, \mathbf{j})$ resolved along the viewing direction, at zenith distance $(\psi)$. In other words we have to obtain the horizontal winds $\mathbf{V}_{\mathbf{h}}(\mathbf{i}, \mathbf{j})$, from the DIS measurements $\mathbf{W}_{\text {ls }}(\mathbf{i}, \mathbf{j})$ by means of:

$$
\mathbf{W}_{\mathbf{l s}}(\mathbf{i}, \mathbf{j})=\mathbf{v}_{\mathbf{h}}(\mathbf{i}, \mathbf{j}) / \operatorname{cosec}(\psi)
$$

Steps to derive the horizontal wind vector $\left(\boldsymbol{V}_{\boldsymbol{h}}(\boldsymbol{i}, \boldsymbol{j})\right)$

For each Fabry-Perot fringe, the DIS obtains a set of 24 line-of-sight radial components $(\mathbf{W}(\mathbf{i}, \mathbf{j}))$ for each of the Fabry-Perot fringes. These individual measurements are processed, as shown, to determine the equivalent set of components of the horizontal wind vector $\left(\mathbf{V}_{\boldsymbol{h}}(\boldsymbol{i}, \boldsymbol{j})\right)$ at each observing point. The tangential wind flow compo- 


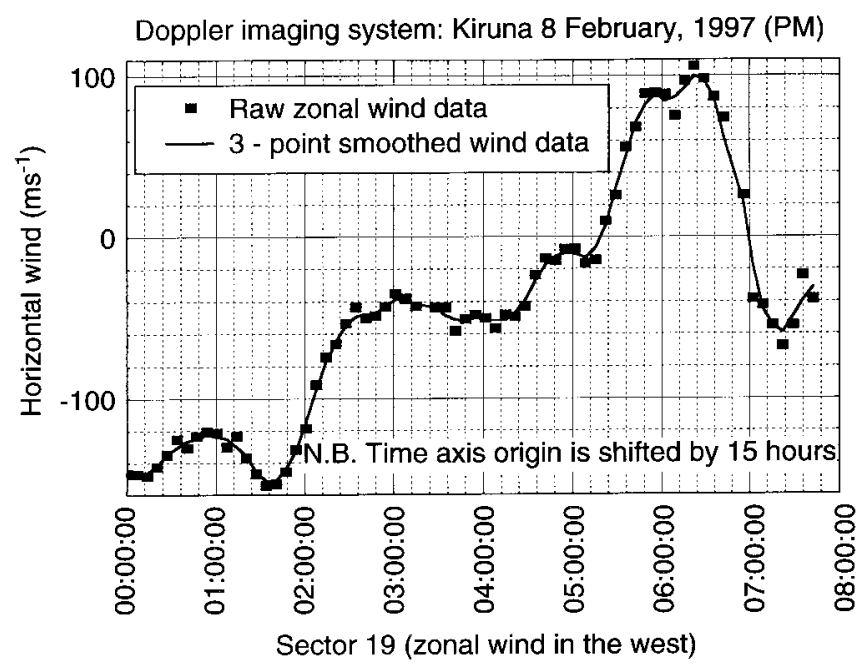

Fig. 10 The zonal wind measurement by DIS p.m. Feb 8 1997: Comparison between $(\boldsymbol{\square})$ raw and $(-)$ smooth values

nent is not measured directly, but may be derived from the data set.

The first harmonic of the Fourier transform of $\mathbf{V}_{\boldsymbol{h}}(\boldsymbol{i}, \boldsymbol{j})$ is the mean wind around a Fabry-Perot fringe:

$\mathrm{V}=\mathrm{A} \cos \theta+\mathrm{B} \sin \theta$

Thus the harmonics $\mathrm{A}$ and $\mathrm{B}$ can be equated to the average wind velocity $V$ and bearing $\phi$ by:

$\mathrm{A}=\mathrm{V} \cos \phi \quad$ and $\quad \mathrm{B}=\mathrm{V} \sin \theta$

Thus, the mean wind direction $(\phi)$ and amplitude $\mathrm{V}$ of the true mean wind are:

$\phi=\arctan (\mathrm{B} / \mathrm{A})$

$\mathrm{V}=\left(A^{2}+B^{2}\right)^{1 / 2}$

This method can be used directly to derive the average flow velocity over a single fringe (i). The method can also be extended to solve for the smaller-scale structures within the wind flow. These are the higherorder Fourier components. This can be done to investigate the small-scale features of the wind flow over the region up to approximately $800 \mathrm{~km}$ diameter sampled by the DIS (for OI $630 \mathrm{~nm}$ observations). A maximum entropy method has been used (Batten, 1988) to determine the optimum truncation of the Fourier series to retain as much detail in the wind pattern, while suppressing small-scale and short-term features which are more likely to be due to noise, rather than real physical features of the thermospheric wind field.

In both cases, the argument which is applied is that the average wind flow must be continuous, and with a continuous gradient. Assuming that vertical winds are limited to realistic values, related to credible energy sources associated with Joule and/or particle heating, the divergence and convergence of the horizontal wind flow must be limited. The technique and its application to observations of thermospheric winds by the DIS is discussed more comprehensively in Batten et al. (1988), Batten (1989) and Rees et al. (1991).
Effect of the vertical wind component on the derivation of the horizontal wind component

There is no question but that vertical winds, sometimes of magnitudes considerably in excess of $10 \mathrm{~m} \mathrm{~s}^{-1}$, occur in the auroral thermosphere (Rees et al. 1984a, b). The first full fringe of the DIS can be used as a reliable estimator of vertical wind overhead the instrument, since:

1. The light comes from a relatively restricted region,

2. The zenith distance is relatively small,

3. The los wind component contains $95 \%$ of the vertical wind, and $10 \%$ of the divergence of the horizontal wind over the $40 \mathrm{~km}$ region.

For the DIS at Kiruna, the diameter of the first full fringe, as projected onto the airglow layer (at approximately $240 \mathrm{~km}$ altitude) is of the order of $40 \mathrm{~km}$. The vertical wind in the upper thermosphere appears to be well correlated over distances up to approximately $50 \mathrm{~km}$. However, the ability of the Kiruna DIS to measure vertical winds by this method during the periods discussed here was compromised, since the calibration lamp was not used routinely, so that any change of optical path difference as a function of time was aliased with the effect of a vertical wind in the region about the zenith.

Generally, with regular use of the neon calibration lamp since September/October 1997 for the two DIS instruments at IRF, Kiruna and at Svalbard, the vertical wind in the zenith will be determined routinely. This will be used to estimate the interference of the vertical wind with the derivation of horizontal winds. Away from the zenith, for example at $45^{\circ}$ zenith distance, the effect of a $50 \mathrm{~m} \mathrm{~s}^{-1}$ vertical wind would be $50 /(2)^{1 / 2}$, or approximately $35 \mathrm{~m} \mathrm{~s}^{-1}$.

In future, it will also be possible to obtain simultaneous thermospheric wind data from three modern FPI instruments in the north Scandinavian region: The DIS at Kiruna, The Max Planck Institute FPI at Skibotn, and the FPI located at ALOMAR. These three instruments have a substantial overlap of their fields-of-view, and the scanning positions of the two FPIs have been adjusted to provide closely proximate views in several locations. Only with such a possibility for tri-static measurements can the three-dimensional wind vector be uniquely determined. Unfortunately, such opportunities will be limited in number by the relative difficulty of obtaining clear tropospheric conditions at all three stations.

\section{Appendix 2: investigation of the random component of wind error for the DIS}

The random component of the wind error is primarily related to two factors:

1. The signal to noise ratio of the Fabry-Perot image,

2. The unknown vertical wind distribution which will vary over the field of view of the DIS.

To investigate the first factor, we have processed several sets of data from the Kiruna DIS during the night of February 8/9 1997. 
Doppler imaging system: Kiruna 9 February 1997 (AM)

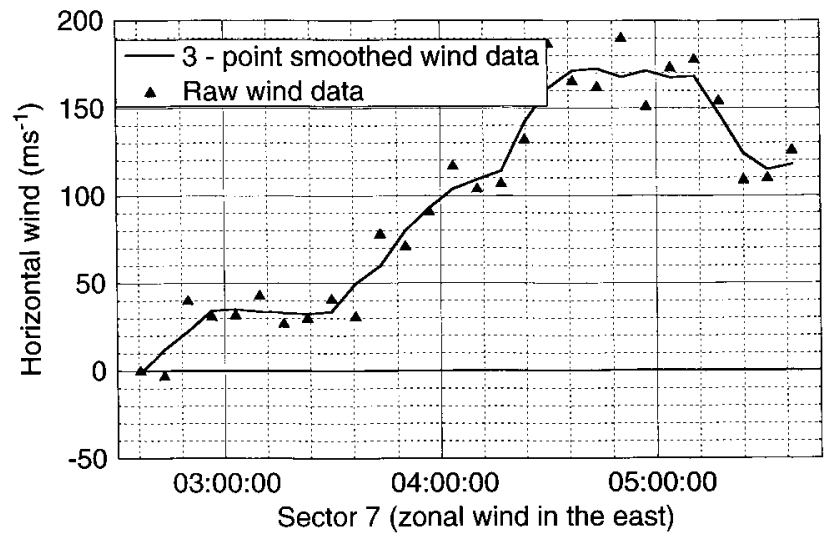

Fig. 11 The zonal wind measurement by DIS a.m. Feb 9 1997: Comparison between ( $\mathbf{\square})$ raw and $(-)$ smooth values

Figure 10 shows the derived horizontal winds for sector 19 (also shown in Fig. 8) during the period between 16:00 and 24:00 UT. This shows that the zonal wind was initially westward, changing to eastward after about 21:00 UT.

Two curves are shown in Fig. 10 The first is the direct result of the Doppler analysis, while the second curve displays the data following a 3-point smoothing (running spline). A statistical analysis of the differences between the raw and smoothed data shows a standard deviation of $5 \mathrm{~m} \mathrm{~s}^{-1}$, and maximum deviations of $20 \mathrm{~m} \mathrm{~s}^{-1}$. This is consistent with the $5 \mathrm{~m} \mathrm{~s}^{-1}$ standard deviation, considering the ample of approximately 100 points. During this period, the OI $630 \mathrm{~nm}$ intensity was consistently moderately bright.

Fig. 11 shows a second comparison for the following morning (morning of 9 February, 1997). In this case, we have chosen the east direction (sector 7). Again, the first curve is the direct result of the Doppler analysis, while the second curve displays the data following a 3-point smoothing (running spline). In this case, when the OI $630 \mathrm{~nm}$ emission levels were significantly lower than during the previous evening, it can be seen that the random differences between the raw and smoothed data are approximately $20 \mathrm{~m} \mathrm{~s}^{-1}$, rather than the $5 \mathrm{~m} \mathrm{~s}^{-1}$ typical of the data shown in Fig. 10.

Neither of these examples can be used to examine the potential effects of vertical winds, although the analysis of the central Fabry-Perot fringe during this period indicated that vertical winds directly overhead Kiruna were of small magnitude, probably always less than $25 \mathrm{~m} \mathrm{~s}^{-1}$.

A considerable effort has subsequently been put into modifying the hardware, electronics and operating software to accommodate a regular spectral calibration of the instrument. This should provide the possibility in the future for accurate measurement of the vertical wind overhead the DIS station at Kiruna. That will only provide knowledge of the conditions overhead, although there is experimental evidence that episodes of high vertical winds are consistently associated with the periods of higher geomagnetic activity. 